\title{
EDITORIAL
}

\section{Rethinking conferences}

\author{
How can physicists reap the benefits of conferences while reducing their environmental impact? \\ New formats, such as online and multisite conferences, may be part of the solution.
}

Last month, photonics researchers from around the world met to discuss integrated optics, nanoscale quantum optics and optical materials. What was unusual about these discussions was that they occurred online and via live-streaming at more than 60 local hubs, as part of the first ever Photonics Online Meetup (POM). This new conference aimed not only to disseminate technical results to the photonics community, but also to promote the mission of reducing the financial cost and environmental impact of conferences, and improve their accessibility. It seems this mission struck a chord: the organizers received more than 100 submissions for the nine speaking slots of POM, according to conference chair Andrea Armani.

It's not hard to see why. On the environmental side, a visible impact of conferences is the waste generated in the form of disposable coffee cups at each break and registration packs for each delegate, which often end up as trash. This waste is relatively easy to reduce, by encouraging the use of reusable cups, or making conference freebies available but not a default part of registration, for example.

But even with such measures in place, physics conferences have a carbon footprint that cannot be ignored. Travel comprises a substantial part of most academics' carbon footprint: for instance, Julien Arsenault and colleagues estimated that professors at Université de Montréal generate on average $10.76 \mathrm{~T}$ of $\mathrm{CO}_{2}$ annually through work-related travel ${ }^{1}$, compared with $13.14 \mathrm{~T}$ of $\mathrm{CO}_{2}$ per annum for the entire footprint of an average Canadian household. These impacts are ingrained in the nature of conferences, which bring delegates from around the world into a single location for a few days.

Undoubtedly, traditional conferences have benefits, such as face-to-face discussions between people who might otherwise not even be aware of each other's work. How can physicists continue to reap the benefits of conferences while reducing their impact? One step that many individuals can take is to consider how they travel $^{2}$. In some cases, trains are a viable alternative to planes, especially within Europe. A trip to a conference might be combined with a visit to collaborators nearby, to make the most of the flight. For researchers who receive many speaking invitations each year, simply attending fewer conferences - or presenting via video link - would lower their individual carbon footprint. These decisions can be supported by universities, who can set travel policies that take into account the environmental cost of travel, and not only the financial cost.

Conference organizers also have a role to play. The positive reception of experimental online conferences, such as POM, shows that there is an appetite for different models of conference. "Faculty are already making commitments to reduce their conference attendance even without an alternative platform," points out Armani. "Online events simply provide an alternative path to ensuring the success of junior faculty who want to travel less but still bring attention to their research."

A compromise between traditional and fully virtual conferences is to split an international conference between two or more geographical hubs, linked to each other by videoconferencing. In one case study, a conference split between hubs in Switzerland and Japan was estimated to have 37-50\% lower travel-related greenhouse gas emissions, compared with a hypothetical single-site alternative ${ }^{3}$. Even traditional conferences can make recordings of talks available online, enabling knowledge dissemination to those who cannot attend in person. Furthermore, a lot of leadership in alternative models for academic conferences has come from other disciplines, and it is worth looking at compilations such as Flying less in academia: a resource guide to see what has already been done.

As editors, we have a responsibility to stay up-todate on what is happening in our communities, and conferences are valuable for this purpose. We also have a responsibility to ensure that the benefits of our travel outweigh its environmental impact. This does not mean boycotting air travel altogether: if we never left London, we would miss out on meeting physicists who do not or cannot travel here. But we are committed to travelling strategically, doing what we can to reduce our carbon footprint by using trains rather than planes whenever practical, and taking advantage of new ways of doing conferences.

1. Arsenault, J. et al. The environmental footprint of academic and student mobility in a large research-oriented university. Environ. Res. Lett. 14, 095001 (2019).

2. Quinton, J. N. Cutting the carbon cost of academic travel. Nat. Rev. Earth Environ. 1, 13 (2020).

3. Coroama, V. C. et al. Effects of Internet-based multiple-site conferences on greenhouse gas emissions. Telem. Inform. 29 362-374 (2012). 